\title{
THE IMPACT OF LEAN TOOLS ON THE LEVEL OF OCCUPATIONAL SAFETY IN METALS FOUNDRIES
}

\author{
${ }^{1}$ Robert ULEWICZ, ${ }^{2}$ Magdalena MAZUR, ${ }^{3}$ Frantisek NOVY \\ ${ }^{1}$ Czestochowa University of Technology, Czestochowa, Poland, EU, robert.ulewicz@wz.pcz.pl \\ ${ }^{2}$ Czestochowa University of Technology, Czestochowa, Poland, EU, magadalnena.mazur@wz.pcz.pl \\ 3University of Zilina, Zilina, Slovak Republic, EU, frantisek.novy@fstroj.uniza.sk
}

https://doi.org/10.37904/metal.2019.992

\begin{abstract}
The article presents the results of research related to the assessment of the impact of the use of selected lean tools on the level of safety in foundries. The factor analysed is the registration of potentially dangerous accidents and events in the foundry. The obtained results for a specific research sample from the foundry industry were referred to the obtained results for the metal processing industry. The obtained results indicate a positive effect of using selected lean tools on the level of security. The number of registered accidents as well as potentially dangerous events has significantly decreased as a function of time.
\end{abstract}

Keywords: Foundry, metal, occupational health, lean tools

\section{INTRODUCTION}

Each enterprise, including companies in the foundry industry, has its own security culture. The main aim of the paper is to determine the impact of using lean tools on the level of accidents and registered events potentially dangerous in the foundries, and to determine whether pro-lean activities positively influence the safety culture. Enterprises are diverse in terms of safety culture, which is influenced by how the organization is managed, for example by implementing the idea of a lean concept or its instruments in the improvement of ongoing processes [1]. Safety culture of an organization may be desirable or undesirable. The safety culture should be treated as a continuous variable whose limit values are: the culture of absolute security and the culture of seeking and reducing risk. The role of safety culture in foundries is created by the employer taking into account legal requirements resulting from the existing regulations. The employer deals with occupational safety and health policy, defines hazards, sets standards for dealing with emergencies and promotes vigilance against the possibility of new threats. The Regulation of the Minister of Development and Finance of 15 December 2017 on occupational health and safety in metal foundries is in force in Poland. The regulation contains detailed guidelines on the handling of batching materials for foundry tips, the method of storage of batch materials and the method of marking. The area where scrap metal is crushed is visibly marked and properly protected against splashing of scrap debris. Also, other provisions of the regulation provide for secondary areas where lean tools can be used to improve efficiency and productivity by eliminating the proverbial waste. The said regulation is not isolated in European or national Czech or Slovak legislation, we have similar recommendations regulating work safety in metal foundries. The mass of liquid metal conveyed by one worker when handing molds manually cannot exceed $25 \mathrm{~kg}$ with the ladle, and the ladle transfer paths should not cross other roads. Forms of flooding molds and their immediate surroundings should have dry floors, and no liquids or flammable materials should be in the immediate vicinity of these stands. Rotating molds at centrifugal casting should be shielded in a way that protects employees against liquid metal spatter.

Among the hazards present in the foundry, the following should be mentioned:

- $\quad$ slippery surfaces at the work site,

- $\quad$ incorrect protection against falling from a height (e.g. inefficient safety barriers), 
- molten metal, metal splashes,

- $\quad$ surfaces of the furnace as well as forms and castings,

- $\quad$ fire during annealing of ladles used for the transport of liquid metal, the possibility of body burns as a result of non-observance of safety instructions during transport,

- $\quad$ explosive elements (including water contained in metal scrap),

- $\quad$ improperly used devices used for cutting and processing of castings and hand tools, means of transport, as a result of poorly marked and designated (or unmarked) transport routes,

- $\quad$ failure to take due care when passing near means of transport (e.g. passing under the crane's suspension with load),

- non-observance of traffic rules by persons driving vehicles transporting materials,

- manual lifting and handling of heavy loads - contrary to the standard or ergonomic requirements,

- $\quad$ ill-chosen or dirty light spots for general and local lighting,

- $\quad$ poorly organized work processes, contrary to safety instructions, furnace operation and process lines,

- dust and gases; noise,

- $\quad$ emotional load and emotional stress caused by, among others shift work and time pressure in performing tasks.

\section{EFFECT OF LEAN CONCEPT ON WORK SAFETY}

The Lean Management philosophy in more and more enterprises becomes a way to comprehensively manage processes in an organization [2]. For over a dozen years, this philosophy is not only associated with production. However, in the metal processing industry, nearly 90 percent of the surveyed enterprises identify it only with the optimization and improvement of work efficiency. However, the effect depends on the set objectives and accepted measures to monitor the effectiveness of implementation. Companies that seriously want to implement the Lean philosophy should start this process by establishing the goals of their organization in the areas of: quality, costs, productivity, efficiency, security and human development [3]. For these purposes, you must then define measurable tasks, and only for these tasks define the required methods and tools. This approach is called Hoshin Kanri (Hoshin from Japanese "direction," "shiny needle", "compass", Kanri from Japanese "management"). This approach became the foundation of the Toyota Production System. The main purpose of this approach is:

- identification of the main problems of the organization,

- structure based on PDCA,

- $\quad$ atmosphere conducive to creativity and hard work.

Methods and tools are very important in the Lean philosophy, but their use should be the effect of previously set goals and specific tasks. In addition, Lean methods and tools not only improve productivity and work efficiency. In Lean, a significant part of the methods is focused primarily on human development (Lean HR, PDCA, Quality Circles, etc.) in the assumption they should also influence the improvement of work safety through the employee's awareness about the processes being carried out. Most often, the Lean philosophy is associated with the elimination of waste. In Lean Management, elimination of waste is a very important element of efficiency improvement, it is all about slimming down the flow of material and information. What this flow disturbs is wastage. The scale of disturbances is the greater, the more people employ the enterprise. Often, employees organize their work, guided by their own needs or habits acquired during their professional activity [4]. In addition to the disturbances typical of production sites, there are also disturbances in auxiliary processes [5]. Observing the course of even the best designed and implemented production processes, it can be noticed that they do not run under ideal conditions, i.e. they are not disturbed by any factors. Two types of interference 
affect each process: random and special [6]. Random factors usually occur in a large number, each of them having a relatively small meaning, leading to variability that must necessarily be identified. Random factors generate disturbances, which should always be counted, their source is not always known, and they affect the parameters of the manufacturing process in a continuous manner with random intensity. They cannot be fully eliminated, but usually their impact is small and results in a slight statistical differentiation of the value of the products' features. The improvement of the process quality can be achieved through organizational changes so as to limit the number of random factors affecting the process or change the process to another [7]. By reducing the random factors affecting the process, we also reduce the probability of potentially dangerous situations, which affects the safety level in the production company. Much more disadvantageous due to the quality of the manufacturing process as well as the level of safety are special interferences [8-10]. Special interferences can be detected and identified as causing changes in the process level. These are interferences most often from the outside, occurring suddenly or their impact is systematic and intensifying [11]. They affect significantly the parameters of the manufacturing process as well as the level of safety. The use of lean tools, for example $5 \mathrm{~S}$ practices, directly affects the reduction of potentially dangerous events [12]. On the other hand, JIT practices can cause internal transport problems by increasing the frequency of deliveries and increasing the possibility of occurrence of a potentially dangerous event [13]. Using a suction system based on Kanban cards, we can achieve a significant variety of products thanks to a faster exchange system [14]. This is positive from the point of view of marketing, because the diversity of the product and its personalization (the objective of Industry 4.0) generates greater demand for products [15]. Based on the literature data, it can be assumed that the know-how and skills acquired during the use of lean tools are beneficial for improving work safety through better understanding of processes as well as potentially dangerous events [16]. VSM can also help to identify the impact of selected factors on the level of safety in an enterprise. Total Productive Maintenance through a comprehensive program of continuous development of employees and organizations and changes in the culture of the production plant in order to maximize the efficiency of machinery and equipment, through constant monitoring and supervision of technical infrastructure provide employees with an attractive and safe work environment while achieving maximum efficiency and productivity.

\section{RESULTS AND DISCUSION}

The classification of the foundries for the research sample was divided into two stages. In the first stage, 30 metal foundries (non-ferrous metals, steel and cast iron), which were positively verified in terms of the actual use of lean tools, were qualified. Foundries have to manufacture for at least 5 years and use or implement lean tools for 2 years. The questionnaire survey supplemented with the expert's interview was used for this verification. Based on the survey, the practical use or implementation of the lean concept tools has been confirmed. In the tested castings, the following tools were confirmed: visual control, standard work, Poka-Yoke, SMED, Total Productive Maintenance (TPM), Kaizen, Value Stream Mapping (VSM), Overall Equipment Effectiveness (OEE), 5S, TWI-Job Methods, 5W2H, 5WHY. The second stage of classification was feedback given by foundries on quantitative and qualitative information about potentially dangerous events and accidents. Only 12 foundries provided information on potentially dangerous events and accidents required in the further part of the research.

Table 1 presents the result of the analysis of the number of potentially dangerous events and accidents registered in 12 metal foundries. Foundries had to have records documenting the level of potentially dangerous events with at least 5 years. Table 1 and Figure 1 provide a summary of the data obtained. The obtained research allows to formulate the thesis that between the analysed features: the number of probably critical incidents and the number of years of lean tools utilization is negative correlation. With the passage of time and gaining experience in the use of lean tools, the number of potentially dangerous events decreases. Based on the available results of the number of potentially dangerous events and accidents in foundries that do not use 
lean tools, it has been found there is the reduction of the $30-40 \%$ of potentially dangerous events in foundries that use these tools.

Table 1 List of critical incidents in 2011-2018 including the period of using lean tools

\begin{tabular}{|c|c|c|c|c|c|c|c|c|c|}
\hline \multirow[t]{2}{*}{ No. } & \multirow{2}{*}{$\begin{array}{c}\text { Years of } \\
\text { using lean } \\
\text { tools }\end{array}$} & \multicolumn{8}{|c|}{ Number of potentially dangerous events in a year } \\
\hline & & 2018 & 2017 & 2016 & 2015 & 2014 & 2013 & 2012 & 2011 \\
\hline 1 & 2 & 5 & 9 & 13 & 15 & 11 & 11 & 10 & 12 \\
\hline 2 & 3 & 2 & 3 & 10 & 14 & 10 & 12 & 17 & 12 \\
\hline 3 & 4 & 4 & 6 & 6 & 7 & 12 & 20 & 15 & 12 \\
\hline 4 & 7 & 2 & 3 & 7 & 10 & 12 & 15 & 18 & 22 \\
\hline 5 & 2 & 5 & 7 & 14 & 8 & 12 & 8 & 8 & 9 \\
\hline 6 & 5 & 3 & 4 & 10 & 16 & 18 & 20 & 25 & 29 \\
\hline 7 & 5 & 2 & 2 & 7 & 12 & 18 & 22 & 21 & 34 \\
\hline 8 & 3 & 5 & 5 & 10 & 18 & 22 & 23 & 25 & 18 \\
\hline 9 & 4 & 5 & 6 & 7 & 7 & 12 & 14 & 12 & 15 \\
\hline 10 & 2 & 4 & 8 & 12 & 16 & 15 & 9 & 11 & 17 \\
\hline 11 & 8 & 2 & 4 & 5 & 5 & 10 & 10 & 15 & 14 \\
\hline 12 & 3 & 2 & 5 & 7 & 12 & 18 & 10 & 14 & 21 \\
\hline
\end{tabular}

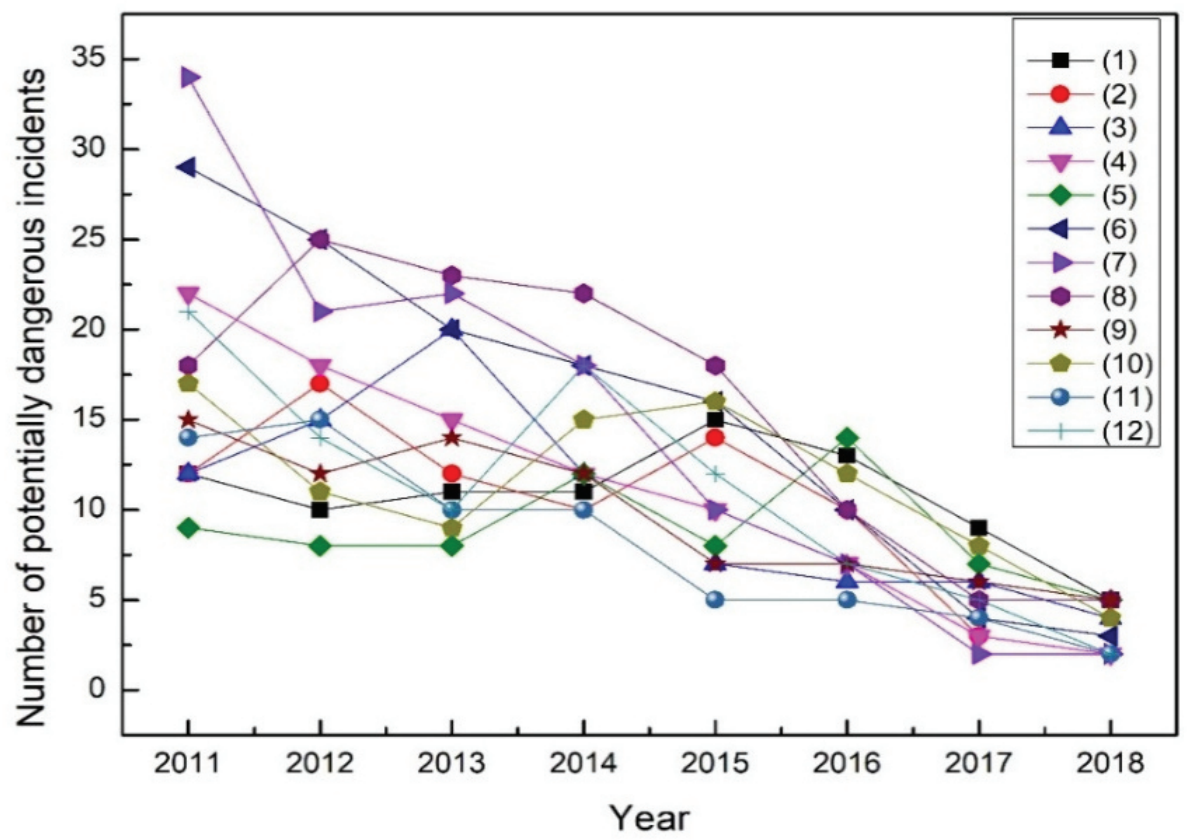

Figure 1 Number of potentially dangerous events in particular years in the tested metal foundries

In the research, an attempt to determine which of the used lean tools, in the opinion of employees, most affect the improvement of the safety level in the foundry, was made. To do so, employees from the 12 foundries were asked to show the importance of each of the used lean tools and to indicate the appropriate position in the priority hierarchy. Then, the Severity Rating W, Equation (1) was calculated [17]. The limitation to the 9 tools is due to the fact that they are used in all analysed 12 entities. 
$W=\frac{\sum_{i=1}^{k} n_{i} w_{i}}{k \sum_{i=1}^{k} n_{i}}$

Where:

$W$ - Severity Rating,

$i$ - indication of tools place,

$k$ - the maximum weight (indication of the order of the tools meant assigning weights in reverse order),

$n_{i}$ - number of indications of given tools on $i$-number place,

$w_{i}$ - weight corresponding to the place of $i$ tools.

The obtained results of the Severity Rating $W$ are shown in Figure 2. The obtained results are similar for the metals processing industry [18]. There were lower values of W coefficient for $5 S$ and higher values in the scope of TPM, OEE and SMED. In the foundries, the employees rated the impact of visual control $(\mathrm{W}=0.8)$ and standard work $(\mathrm{W}=0.7)$ on the level of safety as the most important.

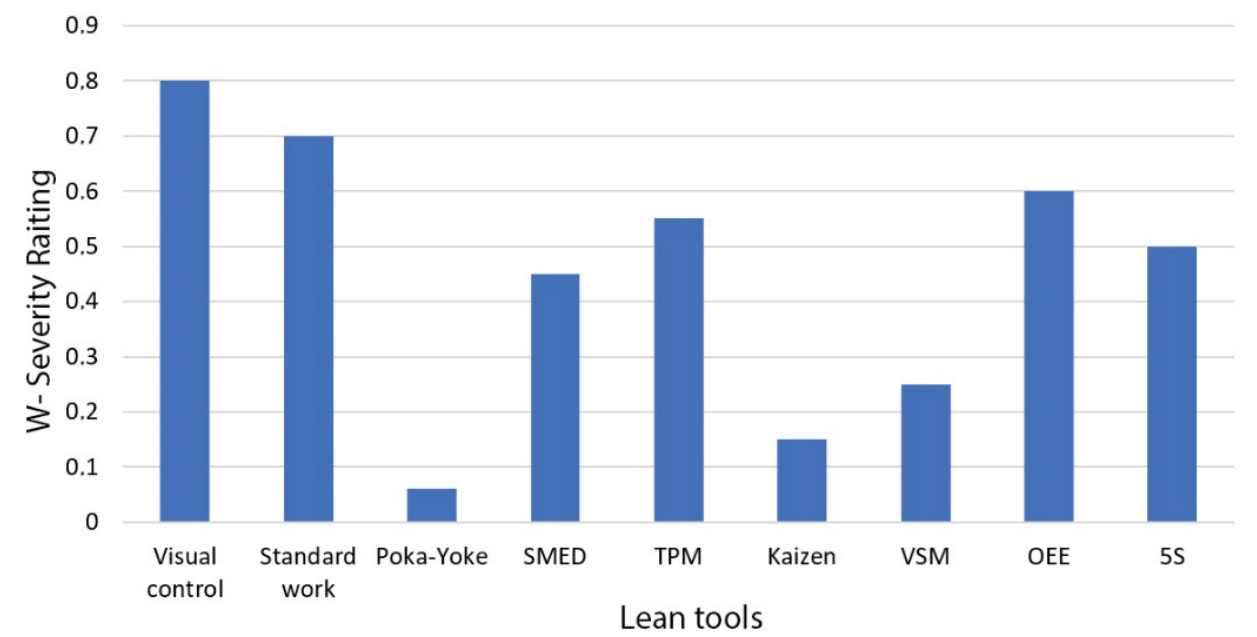

Figure 2 The impact of selected lean tools on the level of safety in the foundries according to workers' opinion

\section{CONCLUSION}

Foundry, despite the progressive implementation of new production technologies - still belongs to areas characterized by a significant level of occupational risk. The reasons for potentially dangerous events can be divided into organizational ones: lack of supervision, insufficient preparation of the employee, toleration of deviations from safety rules, admission of machines without the required control and supervision, incorrect division of labour, tolerance by the supervisor to use improper technology and inappropriate organization of a work station. In the event of technical reasons, we can distinguish: constructional defects or improper technical and ergonomic solution, improper fabrication of the material factor and improper operation of machines and devices. In the case of many identified causes, the use of lean tools eliminates or limits in a significant way the possibility of occurrence of potentially potential events. The impact of using such tools as $5 \mathrm{~S}$, process mapping, standard work, TPM, Kaizen and error-proofing methods contributes to a significant reduction in the occurrence of potentially dangerous events. It should be noted that the number of accidents in foundries has significantly decreased over recent years as a consequence of the automation of many processes in foundries but also as the result of the implementation of safety management systems and a comprehensive approach to process improvement and optimization by eliminating wastage. It may be also useful in so wide areas as the laser machining [19], induction machining [20], X-ray diagnostic [21], pharmaceutical [22] or chemical [23,24] industry. 


\section{REFERENCES}

[1] PAVNASKAR, S. J. GERSHENSON J. K. and JAMBEKAR A. B. Classification scheme for lean manufacturing tools. Int. J. Prod. Res. 2003. vol. 41, no. 13, pp. 3075-3090

[2] BELEKOUKIAS I., GARZA-REYES J. A. and KUMAR V. The impact of lean methods and tools on the operational performance of manufacturing organisations. Int. J. Prod. Res. 2014. vol. 52, no. 18, pp. 5346-5366.

[3] KNOP K. The Impact of performance improvement achieved by the closing machine up to the level of world-class OEE on the Results of the Production Process. In: Szczotok, A., Pietraszek, J. and Radek, N. eds. 10th Conference on Terotechnology, Kielce, 2017, Materials Research Proceedings, vol. 5, pp. 117-122.

[4] GEMBALSKA-KWIECIEŃ, A., SKOTNICKA-ZASADZIEŃ, B., WOLNIAK, R. and BUJNA, M. Creating participation of employees in improving work safety in enterprise. Multidiscip. Asp. Prod. Eng. 2018. vol. 1, pp. 689-694.

[5] PIETRASZEK, J., SKRZYPCZAK-PIETRASZEK, E. The optimization of the technological process with the fuzzy regression. In: SZCZOTOK, A., PIETRASZEK, J., RADEK, N. and GADEK-MOSZCZAK, A. eds. Terotechnology, Advanced Materials Research. 2014, p. 151+.

[6] CUSUMANO, M. The Limits of Lean. Sloan Manage. Rev. 1994, vol. 35, pp. 27-32.

[7] PIETRASZEK, J., KOLOMYCKI, M., SZCZOTOK, A. and DWORNICKA, R. The fuzZy approach to assessment of ANOVA results. In: NGUYEN, NT., MANOLOPOULOS, Y., ILIADIS, L. and TRAWINSKI, B. eds. Computational Collective Intelligence, ICCCI 2016, Lecture Notes in Artificial Intelligence, 2016. pp. 260-268.

[8] MASZKE, A., DWORNICKA, R. and ULEWICZ, R. Problems in the implementation of the lean concept at a steel works - Case Study. MATEC Web Conf [online]. 2018. Vol.183, 01014. [viewed 2019-01-25]. Available from: DOI: 10.1051/matecconf/201818301014

[9] SHRIMALI, A. K., SONI, V. K. A study on the Utilization of Lean techniques/tools in Indian SMEs. Production Engineering Archives. 2018. vol. 20, pp. 32-37.

[10] MAZUR, M., MOMENI, H. LEAN Production issues in the organization of the company - the first stage. Production Engineering Archives. 2018. vol. 21, pp. 36-39.

[11] KOTUS, M., KOLOMAN, K. and HUDEC, M. Assessment of wood processing safety in the production organization. Multidiscip. Asp. Prod. Eng. 2018. vol. 1, pp. 727-737.

[12] SHRIMALI, A.K., SONI, V.K. and PAWAR, S.S. Structural modeling of identified barriers to lean implementation in SMEs. MATEC Web Conf [online]. Vol. 183, 01008. [viewed 2019-01-25]. Available from: DOI: 10.1051/matecconf/201818301008

[13] KÁLOVÁ, K., RAJNOHA, R. and ONDRA, P. The use of industrial lean management methods in the economics practice: an empirical study of the production companies in the Czech Republic. Polish J. Manag. Stud. 2018. vol. 17, pp. 93-104.

[14] MAZUR, M., HASSAN M. Lean production issues in the organization of the company - results. Production Engineering Archives. 2019. vol. 22, pp. 50-53.

[15] STASIAK-BETLEJEWSKA, R., PARV, L. and GLIŃ, W. The Influence of Industry 4.0 on the Enterprise Competitiveness. Multidiscip. Asp. Prod. Eng. 2018. vol. 1, pp. 641-648.

[16] BLASKOVA, M., BLASKO, R., ROSAK-SZYROCKA, J. Flexibility and variability of motivating employees and managers in Slovakia and Poland. Polish J. Manag. Stud. 2017. vol. 15, pp. 26-36.

[17] ULEWICZ R., NOWICKA-SKOWRON M. Total quality management in the practice of polish metallurgical enterprises. In METAL 2017: 26th International Conference on Metallurgy and Materials. Ostrava: TANGER, 2017, pp. 2338-2343.

[18] ULEWICZ, R., LAZART L.V. The effect of lean tools on the safety level in manufacturing organisations. System Safety: Human - Technical Facility - Environment. 2018, vol. 1, pp. 514-521 [viewed 2019-01-25]. Available from: DOI: 10.2478/czoto-2019-0066.

[19] RADEK, N., SZCZOTOK, A., GADEK-MOSZCZAK, A., DWORNICKA, R., BRONCEK, J. and PIETRASZEK, J. The impact of laser processing parameters on the properties of electro-spark deposited coatings. Arch. Metall. Mater. 2018. vol. 63, pp. 809-816. 
[20] SZCZOTOK, A., RADEK, N. and DWORNICKA, R. Effect of the induction hardening on microstructures of the selected steels. In METAL 2018: 27th Int. Conf. Metallurgy and Materials. Ostrava: TANGER, 2018, pp. 12641269.

[21] GADEK-MOSZCZAK, A., PIETRASZEK, J., JASIEWICZ, B., SIKORSKA, S. and WOJNAR, L. The bootstrap approach to the comparison of two methods applied to the evaluation of the growth index in the analysis of the digital X-ray image of a bone regenerate. New Trends in Comput. Collective Intell. 2015. vol. 572, pp.127-136.

[22] SKRZYPCZAK-PIETRASZEK, E., REISS, K., ZMUDZKI, P. and PIETRASZEK, J. Enhanced accumulation of harpagide and 8-O-acetyl-harpagide in Melittis melissophyllum L. agitated shoot cultures analyzed by UPLCMS/MS. PLoS ONE. 2018, vol.13, e0202556.

[23] PACANA, A., BEDNAROVA, L., LIBERKO, I. and WOZNY, A. Effect of selected production factors of the stretch film on its extensibility. Przemysł Chemiczny. 2014. vol. 93, pp. 1139-1140.

[24] PACANA, A., RADON-CHOLEWA, A., PACANA, J. and WOZNY, A. The study of stickiness of packaging film by Shainin method. Przemyst Chemiczny. 2015. vol. 94, pp. 1334-1336. 